\title{
De democracias y dictadores
}

Democracia significa poder del pueblo, pero entre los griegos, que son los creadores de esta modalidad de sistema político, la democracia no pasó de ser un sistema excluyente, ya que los esclavos, la mayoría de la población, no participaban de sus múltiples ventajas; sin embargo, los ciudadanos sí cjercían sus derechos y lo hacían directamente, sin intermediación de los partidos políticos, los cuales no existían. Durante el período feudal no hubo democracia, ya que el poder lo tenían los soberanos, los reyes, los monarcas, y éstos lo delegaban a las distintas categorías de nobles: duques, marqueses, condes, etc. La mayoría de la población, conformada por siervos, artesanos y soldados, estaba excluida del poder, en razón de su sangre plebeya.

Es con el advenimiento del capitalismo que se busca restaurar el concepto de democracia. La naciente burguesía necesitaba arrebatar el poder a los nobles y, para ello, nada mejor que apelar a las insatisfacciones populares, clamando por libertad, igualdad y fraternidad. Surge así una nueva modalidad de democracia: la democracia representativa. Si bien la mayoría de la población no está excluida formalmente de la participación política, ya que cada cierto tiempo se la llama a manifestarse en las urnas para elegir a los gobernantes, buena parte de los gobiernos que han existido han respondido a los intereses de la clase económicamente poderosa. Y cuando, excepcionalmente, el pueblo se ha manifestado a favor de un determinado partido claramente contrario a los intereses burgueses, tales gobiernos han sido cooptados, domesticados 0 , en última instancia, se ha recurrido a los ejércitos para derrocarlos.
La democracia, como régimen político consolidado generalmente en los países capitalistas desarrollados, termina transformándose en un régimen bipartidista, cuyos miembros se alternan en el poder; sin embargo, desde el punto de vista de los intereses populares no existen diferencias fundamentales entre los mismos, tal es el caso de Estados Unidos, el mayor imperio de este siglo, con suficiente poder económico, político y militar para tratar de imponer su sistema político a todos los pueblos del mundo.

Durante la existencia de cierto modelo de socialismo, hegemonizado por la desaparecida Unión Soviética, se intentó construir un nuevo modelo de democracia, fundamentado en el unipartidismo. Teóricamente se justificaba por la inexistencia de clases sociales, por lo tanto, el pueblo, para ejercer su poder, debía elegir a sus representantes de entre los integrantes de su partido: el partido Comunista. En Cuba se sigue, básicamente, este modelo de democracia representativa.

Este recorrido era necesario para desmistificar el concepto de democracia, en tanto que régimen político, y para no confundirla con el régimen económico capitalista. La democracia como régimen político no es ni ha sido exclusiva del capitalismo y no tiene por qué serlo.

Los norteamericanos, dado su régimen político bipartidista formal, puesto que ambos partidos son esencialmente iguales, aunque cambian las personas, han introducido un nuevo requisito o característica a su democracia, que consiste en contrarrestar el poder. Esto es, un sistema de pesos y contrapesos políticos, lo cual, ciertamente, no deja de ser 
un absurdo pretender utilizarlo para calificar de democrático o no a un determinado régimen, ya que, para el caso, si el partido Republicano obtuviera una mayoría aplastante en el senado y en la cámara de representantes y, a su vez, gobernara un presidente republicano, seguramente que no se atreverían a sostener que han perdido la vivencia democrática y que están viviendo bajo una dictadura. En todo caso, sería más acertado sostener que viven bajo una dictadura republicano demócrata, atendiendo al criterio que utilizan para caracterizar a los regímenes democráticos unipartidistas.

Si la democracia postula que la soberanía radica en el pueblo, éste puede legítimamente, en un momento determinado, optar por apoyar masivamente a un determinado partido político, tanto en clecciones presidenciales como de legisladores $\mathrm{e}$, inclusive, de alcaldes, y ello no permite hablar, a no ser abusivamente, de que por ello quien detente la presidencia se haya convertido en un dictador. Es obvio que Hitler no ha pasado a la historia como un dictador, porque llegó al poder con el apoyo masivo de los alemanes. Fueron sus hechos, sus acciones, las que lo convirtieron en un dictador, muy querido por cierto, por la mayor parte del pueblo alemán, gracias a que logró devolverles dignidad y trabajo.

Un gobernante puede, inclusive, llegar al poder de manera ilegítima y legitimarse con sus acciones. O puede llegar al poder legítimamente y acluar de manera impopular, aun existiendo todo el sistema de pesos y contrapesos de que tanto gustan hablar los seguidores de la democracia al estilo norteamericano. Claro ejemplo de ello son los tres gobiernos de ARENA que sufrimos la mayoría de salvadoreños. Afortunadamente, esto es así por decisión de la mayoría. ¡Y nadie se escandaliza!

Se podrá argumentar que la democracia para funcionar también exige de la libertad de expresión, porque sin libertad de expresión los ciudadanos no se pueden manifestar. Eso es correcto y es parte de la crítica que se hace a las democracias populares; no obstante, ello no implica que en los países capitalistas se cuente de manera generalizada con la misma. En países como el nuestro, ahora, y solamente ahora, luego del Acuerdo de Paz, algo hemos avanzado en esta línea. Pero es necesario destacar que la libertad no basta si no se tienen los medios para ejercerla y que los medios de comunicación masiva más importantes son empresas capitalistas, que buscan maximizar sus beneficios a través de la venta de publicidad, y que ésta la compran otros empresarios capitalistas, con lo cual se genera un fuerte sesgo a favor de los mismos y sus intereses.

A pesar de esta realidad inobjetable, la Sociedad Interamericana de Prensa (SIP) sólo condena a los gobiernos que atentan contra su libertad de expresión, la de los empresarios de la industria de la comunicación, pero nunca contra la libertad de los ciudadanos de expresarse libremente. En nuestro maravilloso sistema democrático, la libertad de expresión se compra; si no se tienen los recursos para hacerlo, pues, no se goza de ella a cabalidad. Por otra parte, los intentos de las comunidades organizadas por poseer sus propias emisoras de radio locales, han chocado una y otra vez con la negativa de los gobernantes de turno y con la oposición de los empresarios de la radiodifusión.

Pese a lo anterior, a nadie se le ocurre cuestionar la calidad de la democracia salvadoreña, aunque sí se acusa a los gobernantes de ser los responsables de la miseria, del desempleo, de la incultura, de la delincuencia, de la depredación del medio ambiente y de la exclusión social, cuando la realidad de las cosas es que la mayor responsabilidad, en cuanto a los problemas antes señalados, no recae en los gobernantes - quienes también la tienen-, de los cuales ha habido hasta demócrata cristianos, quienes no se diferenciaron en mucho de los areneros, aun en materia de corrupción, sino en la naturaleza y la esencia del sistema capitalista

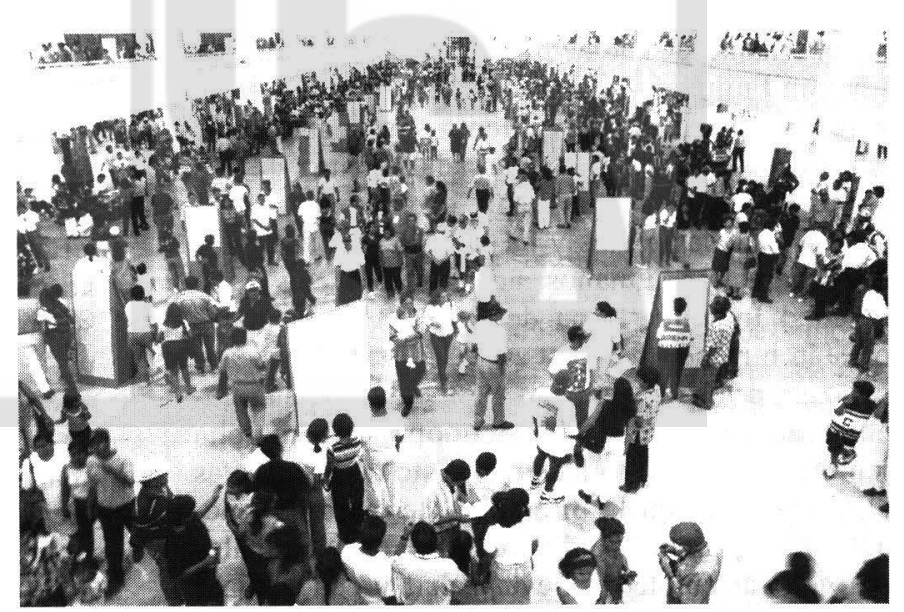


y en la voracidad de la fracción capitalista hegemónica, la cual no sólo controla la economía, sino que también el gobierno.

Pero cuando un pueblo - harto de sufrir toda esta problemática socioeconómica, así como también la corrupción de los partidos tradicionales, sean estos de derecha extrema, social demócratas o demócrata cristianos- clige por aplastante mayoría a un desconocido para las esferas políticas y éste, sin irrespetar las reglas de la democracia, busca lavorecer a las mayorías populares, combatir la corrupción y la impunidad, para lo cual es necesario, obviamente, depurar el poder judicial y además reformar la Constitución política, aparecen las campañas de desinformación en los matutinos conservadores, los cuales nunca se ocuparon de cse país, ni siquiera cuando el "caracazo", que fue la señal de que en Venezuela la población estaba llegando al límite de la tolerancia. Si, adicionalmente, ese desconocido, militar y golpista para más señas, muestra su simpatía por el régimen cubano y por Fidel en particular, aquello ya es motivo de alarma y no se liene ningún reparo en tildarlo de dictador, sin ninguna base ni fundamento para ello.

Cicrtamente, dadas las limitaciones para el desarrollo económico social de nuestros pucblos, que se originan en el modelo de capitalismo globalizado de nuestros días, no es de csperarse que el presidente Chávez de Venezuela logre resolver los múltiples problemas del pueblo venezolano; sin embargo, de seguir en la línea en que hasta ahora ha venido proyectándose, seguramente que sentará las bases para aliviar en mucho la corrupción, la impunidad y la problemática socioeconómica de la población.

Mc parece que es insensato calificar a priori a un gobernante de dictador $-\mathrm{y}$, peor aún, compararlo con Fujimori-; serán los hechos los que mejor juzgarán su desenvolvimiento. Hasta ahora, sus decisiones han estado enmarcadas dentro de los marcos legales, ha jugado el juego democrático sin irrespetar las reglas y ha ganado. No ha violado los derechos humanos, no hay denuncias de la Sociedad Interamericana de Prensa, los capitales no están huyendo de Venezuela ni se está buscando juzgar a los corruptos y a los políticos que gozaban de impunidad. La economía no marcha bien, pero tampoco lo hacen el resto de economías del Cono Sur, con la diferencia de que en Venezuela se están buscando medidas excepcionales para generar empleo y llevar salud y educación a los millones de venezolanos pobres. Se reconoce el hecho paradójico de que Venezuela, un país con tantísima riqueza, tenga al 80 por ciento de su población en la miseria.

Vargas Llosa, conocido escritor peruano de derecha, escribió en el periódico El País de España un artículo sobre el caso venezolano titulado: "El suicidio de una nación". Muchísimas personas, de distintos lugares del mundo, han reaccionado. Pienso que para comprender mejor el caso venezolano, bueno es citar algunos fragmentos de esas opiniones aparecidas en el periódico mencionado.

No sé qué problema tienen las ilustrísimas señorías de América con Chávez, a fin de cuentas fue elegido democráticamente según todas las normas de la democracia occidental, la tan defendida democracia occidental que nos han pintado.

Lo que a mi entender pasa es que ahora esto salió "mal", llegó al poder por la vía en la cual los ricos y demagogos se habían entronado hasta ahora, un hombre con una energía y una historia que no hacen prever más que una verdadera revolución pacífica para Venezuela, lo que inquieta mucho a los vecinos del norte por aquello del petróleo.

Alejandro Delgado, Cuba.

Como la anterior opinión es de un cubano, podría pensarse que se trata de una opinión sesgada, ya que actualmente y luego de la VII Cumbre Iberoamericana, fue manifiesta la simpatía entre Cuba y Venezuela. Veamos la opinión de un ciudadano de Chile, la cuna del neoliberalismo en América Latina:

Al avanzar en la lectura del interesante debate acerca de la realidad venezolana y de su quinta república, creo que centrar el punto en la figura de Hugo Chávez es algo que puede llegar a ser ocioso. Tarde o temprano, el supuesto autoritarismo que muchos achacan a Chávez aflorará (si es tal) o, por el contrario, su proceso culminará con éxito. Sin embargo, creo que un aspecto que es de gran interés es el debate que este proceso plantea acerca de los límites de la democracia para autorreformarse. Si se analizan los párrafos de la Constitución que prepara la Asamblea, aparecen constantes alusiones al Estado protector, al rol de la comunidad solidaria como ente protector de los indivi- 
duos, y rcmarca además el concepto de soberanía popular. Este último concepto, que puede ser papel mojado rápidamente, es la base para un mecanismo de revocabilidad del mandato de los cargos electos que es de bastante novedad en las repúblicas presidenciales como las nuestras. La Constitución de Chávez apunta a retomar la escénica de la democracia y el proceso venezolano cvidencia un conflicto entre esta escénica valórica de la democracia y su expresión formal. El valor de Chávez está en reconocer dicho conflicto y en buscar los caminos de solución pacílica para ello. Chávez no destruyó la democracia venezolana, ésta estaba muerta mucho antes, lo que se evidenció en el "caracazo" y la feroz represión del gobierno de [Carlos Andrés Pérez]. La quinta república explicita esta crisis y asume la necesidad de un cambio. Es imposible saber si el proceso conducirá a una revolución democrática o a una dictadura típica. Lo que sí es posible entender es que la democracia formal venezolana no encontró en sí misma los caminos de la reforma, la ruta hacia su escénica valórica. Basta correr la vista un poco al occidente para ver en Colombia otro caso de democracia formal incapaz de dar curso a los requerimientos de participación de su pueblo. Venezuela y Colombia son interesantes porque, sin haber vivido las criminales dictaduras que nosolros experimentamos en el Cono Sur, experimentan crisis en la aplicación real del modelo y obligan a los demócratas de todas partes a reflexionar sobre la capacidad de nuestros sistemas políticos de constiluir realidades dinámicas, sensibles a las necesidades del soberano (que, con el perdón de los españoles, no es una familia, sino que un pueblo).

Felipe Ossandón Saball, Santiago de Chile.

Y para no abusar del limitado espacio reservado a los comentarios en esta nuestra revista, deseamos presentar la opinión de un ciudadano venezolano:

La verdad, amigos míos, es que después de más de cuatro décadas de corrupción, censura, mentiras y asesinatos impunes, nuestro pueblo decidió en las mesas de votación dar un vuelco a la situación del país. La verdad es que tenemos hoy en Venezuela al gobierno más democrático que haya conocido nuestra historia, donde no se censura a los medios, donde nadie ha ido preso o ha sido hostigado por sus opiniones, donde no asesinan a estudiantes ni obreros. Seguramente que para muchos de ustedes esto no es nada nuevo, pero para nosotros es una nueva y magnífica situación. La verdad es que el gobierno se ha planteado un modelo económico y social humanista que, como primeros logros y apenas en 6 meses, logró aumentar la matrícula escolar en más del 25 por ciento, logró frenar el proceso de inflación, logró frenar la devaluación de la moneda, logró aumentar las reservas del Banco Central, etc., etc.

Tenemos muchos problemas por resolver, y cometemos errores, tal vez muchos, pero tengan la plena seguridad que este proceso es imparable, porque el pueblo así lo ha dictaminado. Sabemos que vamos por buen camino, y cada uno de nosotros hacemos lo que está a nuestro alcance desde nuestro trabajo, nuestro salón de clase, nuestros hogares, pero sobre todo desde nuestro corazón.

\section{Venancio Hernández, Caracas.}

Ciertamente, el proceso venezolano, la experiencia venezolana más que opiniones negativas o juicios emitidos a la ligera, siguiendo la línea de los ultraconservadores, merece ser seguido con atención. Es indiscutible que en Venezuela está ocurriendo algo inédito, y está ocurriendo durante la era de la globalización neoliberal y el predominio casi omnímodo de Estados Unidos. Viviendo como vivimos en un mar de problemas socioeconómicos, con crisis y desconfianza en los partidos políticos, con pocas esperanzas para avanzar hacia un futuro promisorio, un bien nos haría sacar todas las experiencias posibles de la realidad venezolana, ya que nuestra realidad no es muy diferente de aquélla. Pero para ello, más que descalificar la "revolución" pacífica de Chávez, debemos de conocerla, de allí que invito a quienes posean más información sobre este proceso a que la den a conocer.

Aquiles Montoya 